\title{
The Effect in Premature Infants of Prenatal Corticosteroids on Endogenous Surfactant Synthesis as Measured with Stable Isotopes
}

\author{
JAN ERIK H. BUNT, VIRGILIO P. CARNIELLI, J. L. DARCOS WATTIMENA, WIM C. HOP, PIETER J. J. SAUER, \\ and LUC J. I. ZIMMERMANN
}

Department of Pediatrics, Sophia Children's Hospital, Department of Internal Medicine II, University Hospital Rotterdam, and Department of Epidemiology and Biostatistics, Erasmus University, Rotterdam; Department of Pediatrics, University Hospital Groningen, The Netherlands; and Department of Pediatrics, University Hospital Padova, Italy

\begin{abstract}
Most in vitro studies show that prenatal administration of corticosteroids stimulates the synthesis of surfactant phosphatidylcholine (PC), but studies in animals are controversial. Whether prenatal corticosteroids stimulate surfactant PC synthesis in humans has not been studied. We studied endogenous surfactant PC synthesis in relation to prenatal corticosteroid treatment in 27 preterm infants with respiratory distress syndrome. Infants received a 24-h infusion of the stable isotope $\left[\mathrm{U}-{ }^{13} \mathrm{C}\right]$ glucose, starting $\sim 5 \mathrm{~h}$ after birth. We measured ${ }^{13} \mathrm{C}$-incorporation into palmitic acid in surfactant PC from serial tracheal aspirates and in plasma triglycerides and phospholipids by isotope-ratio mass spectrometry. Premature infants had received either zero $(n=11)$, one $(n=4)$, or two doses $(n=12)$ of prenatal betamethasone (12 mg intramuscularly). The fractional synthesis rate (FSR) of surfactant PC from glucose was $1.7 \pm 0.3 \% / \mathrm{d}$ without corticosteroid treatment, $2.9 \pm 1.4 \% / \mathrm{d}$ with one dose of prenatal corticosteroid, and $5.8 \pm 1.3 \% / \mathrm{d}$ after two doses of prenatal corticosteroid. Using multiple regression analysis, we found that the FSR of surfactant PC increased by $40 \%$ (confidence interval: 7 to $82 \% / d, p<0.02$ ) per dose of corticosteroid and doubled after two doses of corticosteroid. The ${ }^{13} \mathrm{C}$ enrichment of plasma triglycerides and phospholipids was not increased by corticosteroid. These data show for the first time that prenatal corticosteroid treatment stimulates surfactant synthesis in the preterm infant.
\end{abstract}

After very premature delivery, many infants develop respiratory distress syndrome (RDS) caused by primary surfactant deficiency, among other factors. Prenatal corticosteroid administration to women at risk for premature delivery reduces the incidence and severity of RDS, as well as reducing mortality in preterm infants (1). Prenatal corticosteroids improve pulmonary function in preterm animals with RDS by stimulating structural development (2), inducing antioxidant enzymes (3), and decreasing vascular permeability (4). Improved pulmonary function can also result from increased amounts of surfactant in the alveolar space. In many in vitro studies, corticosteroids have been found to increase the activity of the enzymes needed for the synthesis of surfactant lipids (5-7) and to increase surfactant protein synthesis $(6,8-10)$. In in vitro experiments with lung slices and isolated type II cells, corticosteroids have been found to increase the incorporation of radiolabeled precursors into surfactant $\mathrm{PC}$, reflecting increased PC synthesis $(5,7,11-13)$. Despite these strong indica-

(Received in original form June 29, 1999 and in revised form January 19, 2000) Supported by grant SSWO 184 from the Sophia Foundation for Medical Research, Rotterdam, The Netherlands.

Correspondence and requests for reprints should be addressed to Luc J. I. Zimmermann, M.D., Ph.D., Neonatology, Sophia Children's Hospital, Dr. Molewaterplein 60, 3015 GJ Rotterdam, The Netherlands. E-mail: Zimmermann@alkg.azr.nl

Am J Respir Crit Care Med Vol 162. pp 844-849, 2000

Internet address: www.atsjournals.org tions for corticosteroid stimulation of PC synthesis, most studies with animals do not show increased surfactant PC pool sizes or increased precursor incorporation after prenatal corticosteroid treatment $(2,4,14-20)$; some studies have reported increased surfactant pool sizes (20-22); and one study found decreased alveolar surfactant pool sizes after a single dose of prenatal betamethasone (23). The amount or concentration of surfactant in the alveolar space does not adequately reflect surfactant synthesis, because both of these variables depend on the amount of surfactant secreted into and cleared from the alveolus.

In a randomized study of preterm baboons, it was recently found that surfactant PC synthesis from glucose was stimulated by two doses of prenatal corticosteroids (24). Whether prenatal corticosteroids stimulate surfactant PC synthesis in preterm infants with primary surfactant deficiency has not been studied. We recently reported data on surfactant metabolism in six premature infants, using a novel and safe technique (25). The present clinical study is the first implementation of our recently developed method. With this technique, involving the use of stable isotopes, we tested the hypothesis that prenatal corticosteroids stimulate surfactant synthesis in critically ill preterm infants with RDS.

\section{METHODS}

\section{Patients and Study Design}

Consecutive infants requiring mechanical ventilation were studied from directly after birth. Inclusion criteria were a gestational age $<32 \mathrm{wk}$, intubation for RDS as defined clinically and by chest radiography (26), and written parental informed consent. Exclusion criteria were congenital infection, maternal diabetes, and chromosomal abnormality. Patients received a constant intravenous infusion of the stable isotope [U- ${ }^{13} \mathrm{C}$ ]glucose (Campro Scientific, Veenendaal, The Netherlands) for $24 \mathrm{~h}$ at $0.17 \mathrm{mg} / \mathrm{kg} / \mathrm{min}$. The start of the study $(\mathrm{t}=0)$ was defined by the start of the isotope infusion. This was $5.3 \pm 0.5 \mathrm{~h}$ (mean $\pm \mathrm{SEM}$ ) after birth. The total glucose intake was $5.7 \mathrm{mg} / \mathrm{kg} / \mathrm{min}$ including nonlabeled glucose, and the infants did not receive any lipids during the first $48 \mathrm{~h}$ of the study. Before and during the glucose infusion, $1 \mathrm{ml}$ of arterial blood was drawn every $6 \mathrm{~h}$ for the determination of ${ }^{13} \mathrm{C}$-enrichment of plasma glucose and of palmitic acid in plasma triglycerides, in phospholipids, and in the free fatty acid fraction. Exogenous surfactant (Survanta; Abbott Laboratories, North Chicago, IL) was administered endotracheally at $\mathrm{t}=0$, at a dose of $100 \mathrm{mg} / \mathrm{kg}$ phospholipids, if the mean airway pressure exceeded $7.5 \mathrm{~cm} \mathrm{H}_{2} \mathrm{O}$, or if the inspiratory oxygen fraction was higher than 0.40 . Infants received a second dose of $100 \mathrm{mg} / \mathrm{kg}$ phospholipids $6 \mathrm{~h}$ later if the foregoing criteria were still met. The attending neonatologist administered a third dose of surfactant $(100 \mathrm{mg} / \mathrm{kg})$, if appropriate, within $20 \mathrm{~h}$ after the second dose.

Tracheal aspirates were obtained every $6 \mathrm{~h}$ during the period that the infant was intubated. Tracheal suctioning was performed during routine patient care, and did not deviate from the normal clinical protocol (25). Tracheal aspirates were immediately frozen at $-20^{\circ} \mathrm{C}$ until further processing. No tracheal suctioning was done within $6 \mathrm{~h}$ after 
TABLE 1

PATIENT CHARACTERISTICS

\begin{tabular}{|c|c|c|c|c|c|}
\hline $\begin{array}{l}\text { Doses of Prenatal } \\
\text { Corticosteroids }\end{array}$ & $\begin{array}{c}\text { Birth Weight } \\
(g)\end{array}$ & $\begin{array}{l}\text { Gestational Age } \\
(w k)\end{array}$ & $\begin{array}{l}\text { RDS Grade } \\
(0-4)\end{array}$ & $\begin{array}{l}\text { Doses of } \\
\text { Surfactant } \\
(n)\end{array}$ & $\begin{array}{c}\text { Days of } \\
\text { Ventilation } \\
(n)\end{array}$ \\
\hline None (Group 0) & $1,035(640-2,030)$ & $29.4(25.9-32.0)$ & $3.5(1-4)$ & $2.0(1-3)$ & $5.5(1.0-51)$ \\
\hline One (Group 1) & $878(590-1,800)$ & $26.6(25.6-31.3)$ & $3.0(2-3)$ & $2.0(1-2)$ & $8.5(5.0-17)$ \\
\hline Two (Group 2) & $905(715-1,270)$ & $27.9(25.6-30.3)$ & $2.5(0-4)$ & $1.5(0-2)$ & $6.8(1.0-39)$ \\
\hline $\mathrm{p}$ Value, 0 versus 2 doses & 0.5 & 0.3 & 0.1 & 0.02 & 0.8 \\
\hline
\end{tabular}

Definition of abbreviation: RDS = respiratory distress syndrome.

surfactant administration. Total parenteral nutrition, including lipids, was started at $\mathrm{t}=48 \mathrm{~h}$.

Infants were grouped according to the number of doses of prenatal corticosteroids that their mother received (one dose $=12 \mathrm{mg}$ dexamathasone intramuscularly). When delivery at admission was expected immediately, corticosteroids were not given (Group 0). When delivery was not expected immediately, the first dose of corticosteroids was given (Group 1). A second dose of corticosteroids was given $24 \mathrm{~h}$ after the first dose if delivery had not occurred (Group 2). The study was approved by the medical ethics committee of the University of Rotterdam and the university hospital.

\section{Surfactant PC Palmitate Isolation}

The tracheal aspirates were processed as previously described (25). In short, cells were removed by centrifugation, internal standard was added, organic extraction was used to isolate surfactant lipids (27), and surfactant PC was isolated by thin-layer chromatography (TLC) (28). The PC was derivatized (29) and the fatty acid methyl esters were stored at $-20^{\circ} \mathrm{C}$. Tracheal aspirates containing visible blood were not analyzed.

\section{Surfactant PC Concentration}

The fatty acid methyl esters were analyzed with gas chromatography (GC), and the quantity of each ester was calculated from the internal standard (30). The concentration of surfactant PC in the epithelial lining fluid (ELF) was calculated by correction for dilution of the ELF during endotracheal suctioning with normal saline, as follows: dilution factor $=$ urea in serum/urea in tracheal aspirate (31).

\section{Blood Samples}

Collected blood was directly centrifuged in order to separate cells from plasma. Through organic solvent extraction, the plasma was divided into a water fraction containing glucose and an organic solvent fraction containing lipids (32). The glucose was isolated with anion and cation exchange resins (25), and was derivatized to an aldonitrile pentacetate derivative (33). From the plasma lipid fraction, triglycerides, phospholipids, and free fatty acids were isolated by TLC, using Kieselgel plates (Merck, Darmstadt, Germany). The solvent system contained heptane/diisopropylether/acetic acid 60:40:3 ( $\mathrm{vol} / \mathrm{vol} / \mathrm{vol})$. The triglycerides, phospholipids, and free fatty acids were derivatized (29) and the fatty acid methyl esters were stored at $-20^{\circ} \mathrm{C}$.

\section{Determination of Enrichment}

The ${ }^{13} \mathrm{C}$-enrichment of palmitic acid in surfactant $\mathrm{PC}$, triglycerides, phospholipids, and free fatty acids, and that of plasma glucose was measured with GC-combustion interface-isotope-ratio mass spectrometry (GC-CI-IRMS) (VG Isotech; Middlewich, Cheshire, UK) $(25,29)$. The enrichment is expressed in atom percent excess (APE), which represents the increase in the percentage of ${ }^{13} \mathrm{C}$ atoms in total $\mathrm{CO}_{2}$ from the combusted compounds above baseline enrichment (before isotope infusion). Enrichments were corrected for the contribution of unlabeled carbon atoms added during derivatization.

\section{Calculations}

Because palmitic acid is by far the most abundant fatty acid in surfactant PC, calculations were performed for this fatty acid only (25). The first appearance of enrichment was defined as the time delay between the start of the $\left[\mathrm{U}_{-}{ }^{13} \mathrm{C}\right]$ glucose infusion and the detection of enriched palmitic acid in surfactant PC. The first appearance of enrichment was calculated by plotting the regression line for the linear increase in the enrichment-versus-time curve and extrapolating it to baseline enrichment $(25,34)$. The fractional synthesis rate (FSR) of surfactant PC is the percentage of the total surfactant PC pool synthesized from glucose per day. The FSR was calculated by dividing the slope of the linear increase in ${ }^{13} \mathrm{C}$-enrichment of PC palmitate by the steady-state ${ }^{13} \mathrm{C}$-enrichment of plasma glucose $(25,34)$. The half-life of surfactant PC was calculated by exponential curve fitting of the downslope of the enrichment-versus-time curve (25).

\section{Statistics}

Data are presented as mean \pm SEM or as median (range). Comparisons between the largest groups of $0(n=11)$ and $2(n=12)$ doses of prenatal corticosteroids were made with the Mann-Whitney U test. To adjust for potential confounding factors in the evaluation of the number of doses of corticosteroids with regard to enrichment, multiple regression analysis was used. In this analysis the FSR had to be transformed logarithmically in order to obtain normally distributed data.

\section{RESULTS}

Twenty-seven infants were included in the study, 11 in Group 0 (no prenatal corticosteroids), four in Group 1 (one dose of prenatal corticosteroids), and 12 in Group 2 (two doses of prenatal corticosteroids) (Table 1). The patient groups were comparable with regard to gestational age, birth weight, and the fraction of infants who were of normal size or small for gestational age. The RDS grade and number of days of ventilation were similar among the study groups (Table 1 ). The ${ }^{13} \mathrm{C}$-enrichment of plasma glucose reached a steady state in all infants between $\mathrm{t}=6$ and $24 \mathrm{~h}$, and was similar in all groups (Group 0:

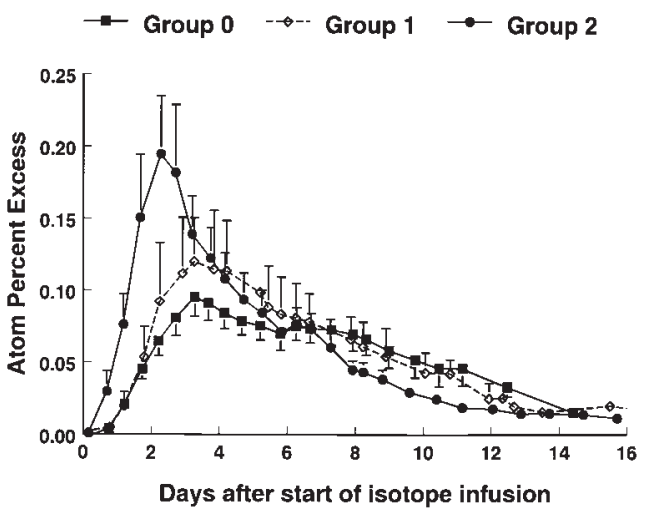

Figure 1. ${ }^{13} \mathrm{C}$-enrichment of palmitic acid in surfactant PC. Ventilated preterm infants received a $24-\mathrm{h}\left[\mathrm{U}-{ }^{13} \mathrm{C}\right]$ glucose infusion as a precursor for PC palmitate. Preterm infants were exposed to zero, one, or two doses of prenatal corticosteroids. The increased synthesis of PC after betamethasone administration is reflected by the increased incorporation of ${ }^{13} \mathrm{C}$ during the first days of life. 
TABLE 2

KINETICS OF SURFACTANT PHOSPHATIDYLCHOLINE IN RELATION TO PRENATAL CORTICOSTEROID TREATMENT

\begin{tabular}{|c|c|c|c|c|c|}
\hline $\begin{array}{l}\text { Doses of Prenatal } \\
\text { Corticosteroid }\end{array}$ & $\begin{array}{c}\text { Time of First Appearance } \\
\text { of Enrichment } \\
(h)\end{array}$ & $\begin{array}{c}\text { Time of Maximal } \\
\text { Enrichment } \\
(h)\end{array}$ & $\begin{array}{l}\text { Half-Life } \\
\quad(h)\end{array}$ & $\begin{array}{l}\text { ctional Synth } \\
\text { Rate } \\
(\% / d)\end{array}$ & $\begin{array}{l}\text { Concentration of PC } \\
\qquad(\mathrm{mg} / \mathrm{ml} E L F)\end{array}$ \\
\hline None (Group 0) & $18.7 \pm 2.8$ & $76.9 \pm 7.8[7]$ & $98.8 \pm 8.3[5]$ & $1.7 \pm 0.3$ & $2.4(0.4-14.3)[5]$ \\
\hline One (Group 1) & $21.3 \pm 2.2$ & $76.8 \pm 7.6[4]$ & $105 \pm 10.9[3]$ & $2.9 \pm 1.4$ & $2.9(1.7-4.2)[2]$ \\
\hline Two (Group 2) & $17.4 \pm 3.0$ & $59.4 \pm 4.0[8]$ & $86.0 \pm 9.9[8]$ & $5.9 \pm 1.3$ & $8.1(0.9-37.5)[9]$ \\
\hline $\mathrm{p}$ Value, 0 versus 2 doses & 0.26 & 0.07 & 0.34 & 0.0002 & 0.19 \\
\hline
\end{tabular}

Definition of abbreviations: ELF = epithelial lining fluid; PC = phosphatidylcholine.

Twenty-seven preterm infants received either zero, one, or two doses of prenatal corticosteroid. The fractional synthesis rate and time of first appearance of enrichment were measured in all infants. Time of maximal enrichment, half-life, and phosphatidycholine concentration were measured in the number of infants, [n], given in brackets.

$2.65 \pm 0.15$ APE; Group 1: $2.28 \pm 0.09$ APE; Group 2: $2.43 \pm$ $0.14 \mathrm{APE})$. Infants in Group 2 required a significantly lower number of doses of surfactant than those in Group 0. (1.5 [0 to 2] and 2.0 [1 to 3], respectively, $\mathrm{p}=0.02$ ). In total, 468 tracheal aspirates were analyzed. The ${ }^{13} \mathrm{C}$-enrichment of palmitic acid in surfactant PC in the three groups is shown in Figure 1. The figure shows an increased ${ }^{13} \mathrm{C}$-enrichment in the corticosteroidtreated groups as compared with Group 0, The kinetic parameters were calculated from these curves and are shown in Table 2. The first appearance of ${ }^{13} \mathrm{C}$-enrichment and the half-life of surfactant PC were similar in the three study groups. There was a trend toward earlier maximal enrichment in Group 2 as compared with Group $0(59.4 \pm 4.0 \mathrm{~h}$ and $76.9 \pm 7.8 \mathrm{~h}$, $\mathrm{p}=0.07)$. The FSR of palmitic acid in surfactant PC from glucose was significantly increased by the administration of prenatal corticosteroids (Figure 2). Univariate analysis of data for Group 0 and Group 2, showed that surfactant synthesis was significantly increased by corticosteroids $(1.7 \pm 0.3 \%$ /d versus $5.9 \pm 1.3 \% / \mathrm{d}, \mathrm{p}=0.0002)$. Because exogenous surfactant dilutes the labeled surfactant PC derived from endogenous synthesis in the type II pneumocyte, we corrected for the number of doses of surfactant administered, using multiple regression analysis. This analysis also allowed correction for the effect of gestational age. The mean FSR increased linearly on a logarithmic scale, with an increase of $40 \%$ (95\% confidence interval: 7 to $82 \%, p<0.02)$ per dose of corticosteroids administered prenatally. This corresponds approximately to a twofold $(1.4 \times 1.4)$ increase after two doses of prenatal corticosteroids as compared with no prenatal treatment.

The liver can use infused $\left[\mathrm{U}_{-}{ }^{13} \mathrm{C}\right]$ glucose for lipogenesis, which results in labeled plasma lipids (25). The type II pneumocyte can use palmitic acid from plasma triglycerides, phospholipids, and free fatty acids for surfactant PC synthesis. Therefore, an increased labeling of surfactant PC after prenatal administration of corticosteroids could in theory result from increased ${ }^{13} \mathrm{C}$-enrichment of plasma lipids, from synthesis by the liver after administration of corticosteroids, with subsequent uptake by lung. To study this possibility, we measured the ${ }^{13} \mathrm{C}$ enrichment of palmitic acid in plasma triglycerides and phospholipids, and in the free fatty acid fraction. The palmitic acid in triglycerides and phospholipids became ${ }^{13} \mathrm{C}$-enriched within $6 \mathrm{~h}$ after the start of the $\left[\mathrm{U}_{-}{ }^{13} \mathrm{C}\right]$ glucose infusion (Figures $3 \mathrm{~A}$ and 3B). The enrichment of free palmitic acid was too low (much lower than that of surfactant PC palmitate) to be measured accurately, and was therefore measured only in several patients (data not shown). There was no statistically significant difference between the groups with regard to ${ }^{13} \mathrm{C}$-enrichment of palmitic acid in plasma triglycerides and phospholipids. These data show that the increased enrichment of surfactant PC palmitate after prenatal administration of corticosteroids was due to increased endogenous synthesis of surfactant PC, and was not a reflection of plasma lipid enrichment. The surfactant PC concentration at birth (before surfactant administration) was 2.4 (0.4 to $14.3 \mathrm{mg} / \mathrm{ml}$ ELF) in Group 0, 2.9 (1.7 to 4.2) $\mathrm{mg} / \mathrm{ml} \mathrm{ELF}$ in Group 1, and 8.1 (0.9 to 37.5) $\mathrm{mg} / \mathrm{ml}$ ELF in Group 2. Although the surfactant PC concentration tended to be higher in Group 2, this was not statistically significant, probably because of the small number of infants studied. The concentration of surfactant PC was measured in only 16 of the 27 patients because some infants had already received exogenous surfactant as therapy before informed consent was obtained for the study.

\section{DISCUSSION}

This study describes for the first time in humans the relation between the exposure to prenatal corticosteroids and de novo surfactant PC synthesis. The clinical study is the first implementation of our recently developed method for evaluating surfactant metabolism with stable isotopes. Preterm infants received $\left[\mathrm{U}_{-}{ }^{13} \mathrm{C}\right]$ glucose as a precursor for the synthesis of palmitic acid in surfactant PC. We found significantly increased surfactant PC synthesis from glucose, with an increase of $40 \%$ per dose of prenatal corticosteroids. This implies that administration of two doses of corticosteroids to the mother at risk of preterm labor, as is generally accepted clinically (35), doubles the production of surfactant PC from glucose in the preterm infant. This finding shows that stimulated general lung maturation is accompanied by increased surfactant PC production.

These findings are in accord with those in many in vitro studies that show induction of enzymes for surfactant synthe-

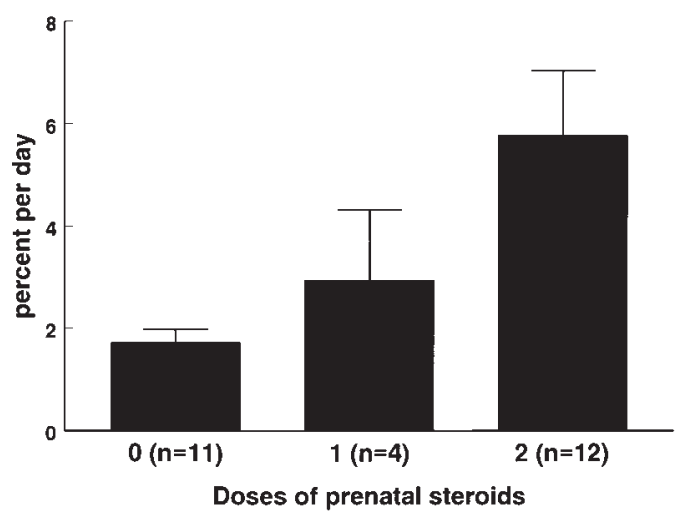

Figure 2. FSR of surfactant PC. Infants received a $24-\mathrm{h}\left[\mathrm{U}-{ }^{13} \mathrm{C}\right]$ glucose infusion, and the ${ }^{13} \mathrm{C}$-enrichment of surfactant PC palmitate was measured throughout the period of ventilation. The difference between zero and two doses was significant $(p<0.001)$. 

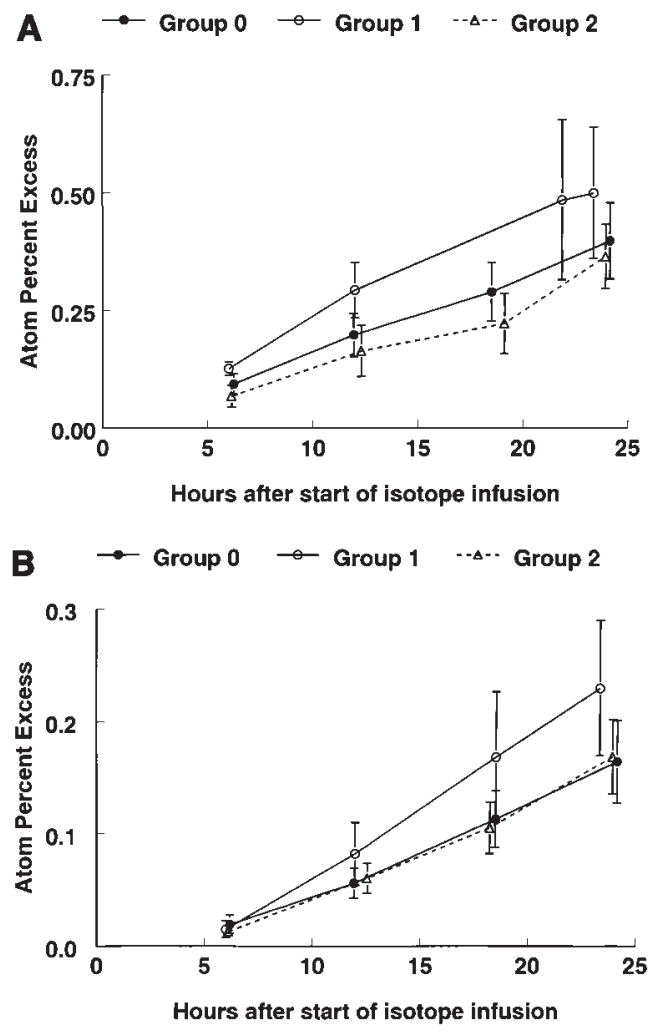

Figure $3 .{ }^{13} \mathrm{C}$-enrichment of plasma triglycerides $(A)$ and of plasma phospholipids $(B)$. After a 24 -h $\left[\mathrm{U}-{ }^{13} \mathrm{C}\right]$ glucose infusion, the ${ }^{13} \mathrm{C}$-enrichment of palmitic acid was measured in these plasma lipids. The ${ }^{13} \mathrm{C}$-enrichment of triglycerides and phospholipids in plasma was not increased by prenatal corticosteroid administration.

sis and increased precursor incorporation after prenatal administration of corticosteroids $(11,12)$. Glucose incorporation into surfactant PC in organotypic cultures of type II cells is increased by betamethasone (12). In a study by Kessler and colleagues of premature baboons, a 72-h treatment with prenatal dexamethasone did not increase incorporation of radioactive palmitate into lung lipids, but shifted the incorporation to disaturated PC in lung lavage fluid $3 \mathrm{~h}$ after birth (20). We recently found that in very preterm baboons that received exogenous surfactant and were ventlilated for $6 \mathrm{~d}$, surfactant PC synthesis from glucose approximately doubled after two prenatal doses of corticosteroids, which is comparable with the findings in the present study (24).

Data on surfactant pool sizes in animal studies as an indication of surfactant synthesis in vivo are conflicting; some studies have found increased pool sizes (20-22), but most studies have not found an increased surfactant pool in the lung after corticosteroid administration $(2,4,14-19)$. We found that the concentration of surfactant PC in ELF tended to increase after two doses of corticosteroids at birth (Table 2). The concentration of PC was measured in only 16 of our 27 patients because some infants had already received exogenous surfactant before informed consent was obtained for their enrollment. In a study by Kari and coworkers of human preterm infants, prenatal dexamethasone had no significant effect on the surfactant concentration in ELF (36). Ballard and associates and Ikegami and colleagues did not find an increased total-lung saturated PC pool size at birth in preterm lambs when corticosteroids were administered from 2 to $4 \mathrm{~d}$ before preterm delivery. However, when corticosteroids were administered 1 wk before delivery, the total lung saturated PC pool at birth had in- creased significantly $(16,21)$. The discrepancies between increased surfactant synthesis and nonsignificantly increased surfactant pool sizes or concentrations in ours and other studies can be explained by the low surfactant synthesis rate relative to the pool size.

The foregoing hypothesis is supported by the other kinetic parameters for surfactant PC generation found in our study (Table 2). The long delay between the start of the stable isotope infusion and the first ${ }^{13} \mathrm{C}$-enrichment of surfactant $\mathrm{PC}$ palmitate shows that the synthesis of palmitate, intracellular processing, and secretion of surfactant into the alveolar space is a slow process. The delay between the start of the isotope infusion and the time of maximal enrichment was long in all groups. The time to maximal enrichment and half-life of surfactant PC tended to be shorter in Group 2, which is compatible with stimulated surfactant metabolism. The long half-lives of ${ }^{13} \mathrm{C}$-enrichment show that endogenously synthesized surfactant remains in the lungs for many days and is diluted slowly by newly synthesized, unlabeled surfactant. The half-lives for phosphatidylglycerol $(\sim 105 \mathrm{~h})$ and sphingomyelin $(\sim 97 \mathrm{~h})$ in preterm infants treated with Survanta were comparable to our data (37). The half-life of phosphatidylglycerol was $\sim 30 \mathrm{~h}$ in preterm infants treated with surfactant extracted from human amniotic fluid (38). In the newborn rabbit, the half-life of surfactant $\mathrm{PC}$ was $\sim 57 \mathrm{~h}$ when labeled with palmitic acid and $\sim 136 \mathrm{~h}$ when labeled with choline (39). Increased clearance of labeled surfactant from the lung shortens the half-lives of its components, and greater recycling of components of surfactant prolongs their half-lives. These variables were not measured in our study, and can affect findings in such studies. The type of surfactant studied and the label used also influence half-life measurements $(37,39)$.

In the present study we measured the synthesis of palmitic acid in surfactant PC only from glucose. Besides glucose, the type II cell has several other sources for the synthesis of surfactant PC, including palmitic acid, intracellular glycogen, lactate, and ketone bodies (40). Glucose is, however, an important substrate for the fatty acids of surfactant PC (41-43), certainly in relative fatty acid deficiency, such as in our infants, in whom intravenous feeding with lipids was begun $48 \mathrm{~h}$ after the start of the isotope infusion. The type II cell can use palmitic acid from the plasma free fatty acid fraction, from plasma triglycerides, and probably from phospholipids for the synthesis of surfactant PC (42). The lung fibroblast accumulates triglycerides and transfers these lipids to the type II pneumocyte, and this process is stimulated in vitro in rat lung by glucocorticoids (44). An increased ${ }^{13} \mathrm{C}$-enrichment of surfactant $\mathrm{PC}$ could therefore be a reflection of increased ${ }^{13} \mathrm{C}$-enrichment of plasma lipids due to stimulated lipogenesis in the liver after prenatal administration of steroids. We measured the ${ }^{13} \mathrm{C}$-enrichment of palmitic acid in plasma free fatty acids, triglycerides, and phospholipids in all three of our study groups. As shown in Figures $3 \mathrm{~A}$ and $3 \mathrm{~B}$, the ${ }^{13} \mathrm{C}$-enrichment of triglycerides and phospholipids did not change after prenatal steroid administration, and could not have led to increased ${ }^{13} \mathrm{C}$-incorporation into surfactant in the corticosteroid-treated groups. The ${ }^{13} \mathrm{C}$-enrichment of palmitic acid in the free fatty acid fraction was too low to be measured accurately (much lower than that of surfactant PC), and was therefore measured only in some patients (data not shown). Thus, the increased incorporation of ${ }^{13} \mathrm{C}$ from glucose into surfactant $\mathrm{PC}$ found in Groups 1 and 2 does not reflect a ${ }^{13} \mathrm{C}$-enrichment of plasma lipids, but rather reflects increased surfactant phospholipid synthesis from glucose. The increased FSR of surfactant $\mathrm{PC}$ reflects the principle that prenatal steroids increase surfactant phospholipid production in the preterm infant, but the extent of the to- 
tal absolute increase is unclear, since the contribution of the other precursors was unknown.

The total surfactant pool and the pools of the metabolic intermediates are unknown, but are influenced by treatment with large amounts of exogenous surfactant. We corrected for the potential confounding effects of the number of doses of exogenous surfactant through multiple regression analysis. As a result of the way in which we enrolled our patients, the different groups could have been subject to different durations of prenatal stress. The impact of such prenatal stress was, however, unknown, which constitutes a limitation of our study. Nevertheless, it is ethically impossible to perform a study such as ours with preterm infants in a randomized fashion, since administration of prenatal corticosteroids is an established therapy for improving outcome for premature infants. However, in a randomized study of premature baboons, we found a comparable increase in surfactant PC synthesis after treatment with prenatal corticosteroids (24).

In summary, this study shows for the first time that prenatal corticosteroid treatment increases surfactant $\mathrm{PC}$ production from the important precursor glucose in the preterm infant with severe RDS. The data show that endogenous surfactant metabolism is a slow process, and that stimulation of surfactant synthesis by steroids probably increases alveolar surfactant pool sizes only after many days. Therefore, the increased surfactant synthesis found after the generally recommended corticosteroid treatment of pretrem infants (35), probably plays only a minor role in the reduced incidence of RDS and improved outcome of this patient population. The accelerated development of the surfactant system is part of the enhanced integrated development of the lung.

Acknowledgment: The authors thank Daphne J. M. T. Janssen of the Department of Pediatrics, Sophia Children's Hospital, Rotterdam, The Netherlands, for excellent technical assistance, and the nursing staff, residents, and neonatologists of the Sophia Children's Hospital for their help and support with this study.

\section{References}

1. Crowley, P. A. 1995. Antenatal corticosteroid therapy: a meta-analysis of the randomized trials, 1972 to 1994. Am. J. Obstet. Gynecol. 173:322-335.

2. Beck, J. C., W. Mitzner, J. W. Johnson, G. M. Hutchins, J. M. Foidart, W. T. London, A. E. Palmer, and R. Scott. 1981. Betamethasone and the rhesus fetus: effect on lung morphometry and connective tissue. Pediatr. Res. 15:235-240.

3. Walther, F. J., A. H. Jobe, and M. Ikegami. 1998. Repetitive prenatal glucocorticoid therapy reduces oxidative stress in the lungs of preterm lambs. J. Appl. Physiol. 85:273-278.

4. Ikegami, M., D. Berry, T. Elkady, A. Pettenazzo, S. Seidner, and A. Jobe. 1987. Corticosteroids and surfactant change lung function and protein leaks in the lungs of ventilated premature rabbits. J. Clin. Invest. 79:1371-1378.

5. Rooney, S. A., L. I. Gobran, P. A. Marino, W. M. Maniscalco, and I. Gross. 1979. Effects of betamethasone on phospholipid content, composition and biosynthesis in the fetal rabbit lung. Biochim. Biophys. Acta 572:64-76.

6. Ballard, P. L. 1989. Hormonal regulation of pulmonary surfactant. Endocr. Rev. 10:165-181.

7. Post, M., A. Barsoumian, and B. T. Smith. 1986. The cellular mechanism of glucocorticoid acceleration of fetal lung maturation: fibroblastpneumonocyte factor stimulates choline-phosphate cytidylyltransferase activity. J. Biol. Chem. 261:2179-2184.

8. Ballard, P. L., R. Ertsey, L. W. Gonzales, and J. Gonzales. 1996. Transcriptional regulation of human pulmonary surfactant proteins SP-B and SP-C by glucocorticoids. Am. J. Respir. Cell Mol. Biol. 14:599-607.

9. Liley, H. G., R. T. White, R. G. Warr, B. J. Benson, S. Hawgood, and P. L. Ballard. 1989. Regulation of messenger RNAs for the hydrophobic surfactant proteins in human lung. J. Clin. Invest. 83:1191-1197.

10. Mariendieck, W., and E. Crouch. 1994. Modulation of surfactant protein D expression by glucocorticoids in fetal rat lung. Am. J. Respir. Cell Mol. Biol. 10:419-429.

11. Gonzales, L. W., P. L. Ballard, R. Ertsey, and M. C. Williams. 1986. Glu- cocorticoids and thyroid hormones stimulate biochemical and morphological differentiation of human fetal lung in organ culture. J. Clin. Endocrinol. Metab. 62:678-691.

12. Sanders, R. L., M. J. Engle, and W. H. Douglas. 1981. Effect of dexamethasone upon surfactant phosphatidylcholine and phosphatidylglycerol synthesis in organotypic cultures of type II cells. Biochim. Biophys. Acta 664:380-388.

13. Tsao, F. H., G. R. Gutcher, and R. D. Zachman. 1979. Effect of hydrocortisone on the metabolism of phosphatidylcholine in maternal and fetal rabbit lungs and livers. Pediatr. Res. 13:997-1001.

14. Chen, C. M., M. Ikegami, T. Ueda, D. H. Polk, and A. H. Jobe. 1995. Exogenous surfactant function in very preterm lambs with and without fetal corticosteroid treatment. J. Appl. Physiol. 78:955-960.

15. Ikegami, M., D. H. Polk, A. H. Jobe, J. Newnham, P. Sly, R. Kohen, and R. Kelly. 1995. Postnatal lung function in lambs after fetal hormone treatment: effects of gestational age. Am. J. Respir. Crit. Care Med. 152:1256-1261.

16. Ikegami, M., D. H. Polk, A. H. Jobe, J. Newnham, P. Sly, R. Kohan, and R. Kelly. 1996. Effect of interval from fetal corticosteriod treatment to delivery on postnatal lung function of preterm lambs. J. Appl. Physiol. 80:591-597.

17. Ikegami, M., D. Polk, and A. Jobe. 1996. Minimum interval from fetal betamethasone treatment to postnatal lung responses in preterm lambs. Am. J. Obstet. Gynecol. 174:1408-1413.

18. Polk, D. H., M. Ikegami, A. H. Jobe, J. Newnham, P. Sly, R. Kohen, and R. Kelly. 1995. Postnatal lung function in preterm lambs: effects of a single exposure to betamethasone and thyroid hormones. Am. J. Obstet. Gynecol. 172:872-881.

19. Seidner, S., E. Rider, A. Jobe, T. Yamada, and M. Ikegami. 1992. Effects of antenatal thyrotropin-releasing hormone, antenatal corticosteroids, and postnatal ventilation on surfactant mobilization in premature rabbits. Am. J. Obstet. Gynecol. 166:1551-1559.

20. Kessler, D. L., W. E. Truog, J. H. Murphy, S. Palmer, T. A. Standaert, D. E. Woodrum, and W. A. Hodson. 1982. Experimental hyaline membrane disease in the premature monkey: effects of antenatal dexamethasone. Am. Rev. Respir. Dis. 126:62-69.

21. Ballard, P. L., Y. Ning, D. Polk, M. Ikegami, and A. H. Jobe. 1997. Glucocorticoid regulation of surfactant components in immature lambs. Am. J. Physiol. 273:L1048-L1057.

22. Platzker, A. C., J. A. Kitterman, E. J. Mescher, J. A. Clements, and W. H. Tooley. 1975. Surfactant in the lung and tracheal fluid of the fetal lamb and acceleration of its appearance by dexamethasone. Pediatrics 56:554-561.

23. Sun, B., A. Jobe, E. Rider, and M. Ikegami. 1993. Single dose versus two doses of betamethasone for lung maturation in preterm rabbits. Pediatr. Res. 33:256-260.

24. Bunt, J. E. H., V. P. Carnielli, S. R. Seidner, M. Ikegami, J. L. D. Wattimena, P. J. J. Sauer, A. H. Jobe, and L. J. I. Zimmermann. 1999. Metabolism of endogenous surfactant in premature baboons and effect of prenatal steroids. Am. J. Respir. Crit. Care Med. 160:1481-1485.

25. Bunt, J. E. H., L. J. I. Zimmermann, J. L. D. Wattimena, R. H. van Beek, P. J. J. Sauer, and V. P. Carnielli. 1998. Endogenous surfactant turnover in preterm infants measured with stable isotopes. Am. J. Respir. Crit. Care Med. 157:810-814.

26. Giedion, A., H. Haefliger, and P. Dangel. 1973. Acute pulmonary X-ray changes in hyaline membrane disease treated with artificial ventilation and positive end-expiratory pressure (PEEP). Pediatr. Radiol. 1:145-152.

27. Bligh, E. G., and W. J. Dyer. 1959. A rapid method of total lipid extraction and purification. Can. J. Biochem. Physiol. 37:911-917.

28. Touchstone, J. C., J. C. Chen, and K. M. Beaver. 1979. Improved separation of phospholipids in thin layer chromatography. Lipids 15:61-62.

29. Carnielli, V. P., E. J. Sulkers, C. Moretti, J. L. Wattimena, J. B. van Goudoever, H. J. Degenhart, F. Zacchello, and P. J. Sauer. 1994. Conversion of octanoic acid into long-chain saturated fatty acids in premature infants fed a formula containing medium-chain triglycerides. Metabolism 43:1287-1292.

30. IJsselstijn, H., L. J. I. Zimmermann, J. E. H. Bunt, J. C. de Jongste, and D. Tibboel. 1998. Prospective evaluation of surfactant composition in bronchoalveolar lavage fluid of infants with congenital diaphragmatic hernia and of age-matched controls. Crit. Care Med. 26:573-580.

31. Hallman, M., T. A. Merritt, T. Akino, and K. Bry. 1991. Surfactant protein A, phosphatidylcholine, and surfactant inhibitors in epithelial lining fluid: correlation with surface activity, severity of respiratory distress syndrome, and outcome in small premature infants. Am. Rev. Respir. Dis. 144:1376-1384.

32. Folch, J., M. Lees, and H. S. Stanley. 1957. A simple method for the isolation and purification of total lipids from animal tissues. J. Biol. Chem. 226:497-509. 
33. Pfaffenberger, C. D., J. Szafranek, M. G. Horning, and E. C. Horning. 1975. Gas chromatographic determination of polyols and aldoses in human urine as polyacetates and aldononitrile polyacetates. Anal. Biochem. 63:501-512.

34. Ballmer, P. E., M. A. McNurlan, E. Milne, S. D. Heys, V. Buchan, A. G. Calder, and P. J. Garlick. 1990. Measurement of albumin synthesis in humans: a new approach employing stable isotopes. Am. J. Physiol. 259:E797-E803.

35. Anonymous. 1994. Effect of corticosteroids for fetal maturation on perinatal outcomes, NIH Consensus Statement. FASEB J. 12:1-24.

36. Kari, M. A., T. Akino, and M. Hallman. 1995. Prenatal dexamethasone and exogenous surfactant therapy: surface activity and surfactant components in airway specimens. Pediatr. Res. 38:676-684.

37. Griese, M., P. Dietrich, and D. Reinhardt. 1995. Pharmacokinetics of bovine surfactant in neonatal respiratory distress syndrome. Am. J. Respir. Crit. Care Med. 152:1050-1054.

38. Hallman, M., T. A. Merritt, M. Pohjavuori, and L. Gluck. 1986. Effect of surfactant substitution on lung effluent phospholipids in respiratory distress syndrome: evaluation of surfactant phospholipid turnover, pool size, and the relationship to severity of respiratory failure. Pediatr. Res. 20:1228-1235.

39. Jobe, A. H., E. Kirkpatrick, and L. Gluck. 1978. Lecithin appearance and apparent biologic half-life in term newborn rabbit lung. Pediatr. Res. 12:669-675.

40. Patterson, C. E., and R. A. Rhoades. 1989. Substrate utilization in the perinatal lung. Am. J. Physiol. 257:L318-L330.

41. Batenburg J. J., W. J. Longmore, and L. M. van Golde. 1978. The synthesis of phosphatidylcholine by adult rat lung alveolar type II epithelial cells in primary culture. Biochim. Biophys. Acta 529:160-170.

42. Rooney, S. A. 1989. Fatty acid biosynthesis in developing fetal lung. Am. J. Physiol. 257:L195-L201.

43. Maniscalco, W. M., J. N. Finkelstein, and A. B. Parkhurst. 1983. De novo fatty acid synthesis by freshly isolated alveolar type II epithelial cells. Biochim. Biophys. Acta 751:462-469.

44. Nunez, J. S., and J. S. Torday. 1995. The developing rat lung fibroblast and alveolar type II cell actively recruit surfactant phospholipid substrate. J. Nutr. 125:1639S-1644S. 